\title{
Coping in complex, changing classroom contexts: An investigation of the bases of pre-service teachers' pedagogic reasoning
}

\section{Dale Langsford}

School of Education, University of the Witwatersrand, Johannesburg, South Africa dale.langsford@wits.ac.za

https://orcid.org/0000-0002-9142-5754

(Received: 14 September 2020; accepted: 26 April 2021)

\section{Abstract}

Despite its central role in enabling professional judgements and decision-making in teaching, pedagogic reasoning is a slippery concept and difficult to pin down. Although pedagogic reasoning is understood to inform all aspects of teaching practice, we still do not know what pedagogic reasoning looks like. In this article, I present a conceptual tool, using concepts from Legitimation Code Theory (Maton, 2014), to explore analytically the differences between the abstraction and context-embeddedness of ideas expressed in the pedagogic reasoning of a sample of pre-service teachers. I argue that pre-service teachers who are able to draw on specialised concepts associated with context-independent principles, may be in a better position to distinguish the "formal elements" from the "material elements" of teaching (Morrow, 2005, p. 98). Being able to make this distinction is likely, I argue, to set pre-service teachers up to cope in complex changing classroom contexts.

Keywords: initial teacher education, pedagogic reasoning, changing contexts, Legitimation Code Theory, semantic gravity, pre-service teachers

\section{Problem: Pedagogic reasoning is important, but difficult to teach}

The core responsibility of teachers is to enable epistemological access to powerful knowledge (Morrow, 1992) to all learners, irrespective of the contexts in which teachers find themselves. In his seminal work that reclaimed the role of content knowledge in professional teaching, Shulman (1987) presented a model that placed the concept of pedagogic reasoning at the heart of all that the teacher does in his or her professional practice. He draws on the argument that "good teaching ... must rest on a foundation of adequately grounded premises" (Shulman, 1987, p. 13). In this article, I investigate the ways in which a sample of pre-service 
teachers justify their pedagogic reasoning about an observed lesson. I analyse the sources from which participants draw criteria for their justification of their pedagogic reasoning. First, I argue that pedagogic reasoning is central to the work of teachers, but is difficult to teach during initial teacher education programmes.

Despite its central role in professional teaching, pedagogic reasoning and judgement cannot be taught in the way that teaching strategies or educational theories can. The ability to engage in powerful pedagogic reasoning in order to promote epistemological access (Morrow, 1992) for all learners is not intuitive. Pedagogic reasoning and judgement cannot be taught because these are context- and topic-specific deliberations (Bransford et al., 2005). A capacity for pedagogic reasoning must be developed in response to a set of ethical principles, understanding of the purposes of the practice, understanding of the processes of teaching and learning, as well as in relation to the specific contextual demands of the classroom (Shulman, 1999).

Drawing on the findings of my doctoral study (Langsford, 2020), this research focuses on the development of pedagogic reasoning in relation to the specific contextual demands of the classroom. There are rationales and decisions to be made based on the teacher's knowledge base that provides the criteria for the decisions. In addition to highlighting the need for and importance of pedagogic reasoning, initial teacher education programmes can teach many of the different knowledge bases from which pre-service teachers can draw the criteria for their pedagogic reasoning. These knowledges usually fall into one of the following categories: "general education theory; pedagogic/methods study; disciplinary/subject matter studies; and school-based experience" (Reeves \& Robinson, 2014, p. 237). Additionally, initial teacher education programmes provide pre-service teachers with opportunities to develop these abilities.

At one South African university, the development of a "rationale for lesson design" requires pre-service teachers to think systematically about the complexities of lesson planning. The guidelines that are presented to pre-service teachers aim to "[present] decision-making in lesson planning as a complex interplay between the components of [professional teacher knowledge], but [enable] pre-service teachers to work systematically through that complexity" (Rusznyak \& Walton, 2011, p. 280). Still, this guideline does not teach preservice teachers to reason or make professional judgements. It provides only scaffolding for pre-service teachers to draw on their knowledge bases to develop their pedagogic reasoning and judgement in situ, and to get feedback from a more experienced other who can interrogate the appropriateness (and legitimacy) of their basis for judgement. It is the responsibility of teacher educators to design opportunities that require pre-service teachers to undertake this knowledge-building work as they learn to teach.

Initial teacher education programmes can then, at best, set up the foundations of knowledge upon which reasoned rational judgements can be made and justified, but it is ultimately up to the pre-service teachers themselves to reason about their decisions, and act in pedagogicly responsive ways in their particular classrooms and contextual realities. Their ability to draw on educational theory, experiences, and practical knowledge of teaching informs their 
"situational appreciation" (Morrow, 1996, p. 80) which, in turn, informs their pedagogic reasoning and professional judgement in situ. Situational appreciation refers to the teacher's ability to distinguish salient cues in the teaching and learning environment that require action. Situational appreciation is a very important aspect of pedagogic reasoning because without the ability to pick out what is important to consider when planning, teaching, or evaluating a lesson, the teacher is unable to make decisions that are pertinent to the specific needs of the classroom (Morrow, 1996).

So far, in this article I have argued that pedagogic reasoning is central to the work that teachers do, but is very difficult to teach during initial teacher education. I have made the argument that initial teacher programmes can set up the conditions for the development of pedagogic reasoning, but that the development of the specialist ways of thinking that are required to engage in pedagogic reasoning must happen in response to particular classrooms and contexts. In the next section, I argue that context-independent principles of teaching provide an organising framework in which pre-service and in-service teachers could organise systematic learning in all teaching and learning contexts.

\section{The role of context-independent principles to navigate changing contexts}

Given the mandate of all teachers to enable epistemological access to knowledge for all learners in any teaching and learning context (Morrow, 1992), what knowledge should preservice teachers draw on in order to engage in pedagogic reasoning? Powerful teaching in changing complex contexts requires a process of critical pedagogic reasoning that is informed by educational theory. Abstracted principles of teaching enable teachers to "distinguish between the formal elements of teaching (which operate in all instances of teaching and are therefore context-independent), and the material elements which 'are necessarily rooted in specific contexts"' (Morrow, 2005, cited in Rusznyak, 2015, p. 21, emphases in Rusznyak's original). When teachers can distinguish between the formal and material elements of teaching, they can draw on the criteria for good teaching that is a mainstay in all classrooms, and not just in particular classroom contexts.

The likes of Shalem (2014), Shulman (1987, 1998), and Winch (2012) have argued that educational theory "binds" (Shalem, 2014, p. 93) pedagogic reasoning and professional judgement. But these scholars are not advocating the simple application of normative rules in the context of the classroom. Indeed, Shulman (1987), made a strong argument that pedagogic content knowledge (which has become widely considered to be the definitive base of the professional teacher) requires reasoned amalgamation. Simply put, pedagogic content knowledge is the "blending of content and pedagogy into an understanding of how particular topics, problems, or issues are organized, and presented for instruction" (Shulman, 1987, p. 8 ). This blending requires teachers to use their knowledge base (theoretical or situational knowledge) in order to reason about and legitimise their actions (practice), as well as to think relationally about all aspects of the lesson and broader educational environment in order to enable epistemological access to knowledge for all learners. 
While pedagogic reasoning is not the same as Pedagogic Content Knowledge, the latter is a useful and powerful knowledge base that pre-service and qualified teachers alike use in order to engage in meaningful pedagogic reasoning. Shulman (1998) claimed that pedagogic reasoning and its resultant judgements are core to navigating a professional practice like teaching and asserted that the "only way to get from there [theory] to here [practice] is via the exercise of judgement" (p. 519, emphasis in original). Teachers need a lens or framework that is informed by educational theory (Winch, 2012), with which to understand and reflect on their practice; this is what Winch (2012) calls "a conceptual toolbox for thinking about educational problems" (p. 4). Hugo (2013) has argued that ideas that are derived from educational theory are non-negotiable informants of pedagogic reasoning and decisionmaking in teaching.

When pedagogic reasoning draws on a knowledge base that is derived from personal experiences of teaching, or on knowledge of specific classroom contexts, it is not easily transferrable from one context to another, nor is it systematised. (At best, it draws on educational ideas in a haphazard way, based on the demands of the context in which teachers find themselves as Rusznyak, 2015, has reminded us.) While teachers may be able to engage in pedagogic reasoning to enable epistemological access for all learners for a while, it is unlikely that they would cope with a changing classroom context because they do not have access to a systematised, abstracted body of educational knowledge and principles. They are therefore less likely to be able to distinguish between the "formal" and "material" elements of teaching (Morrow, 2005, p. 98) when engaging in pedagogic reasoning, and this, then, poses a challenge when they need to navigate different circumstances under which they need to teach.

It is important to note that I am not saying that they will not be able to engage in pedagogic reasoning to enable their practice: they may be in a better position to thrive in the kind of classroom context for which they were prepared or in which they have personal experiences. It may be the case that pre-service teachers' pedagogic reasoning might be constrained because they lack a systematised way in which to think about the demands of teaching and learning in a changing classroom context.

I have argued that educational theory and abstract principles of teaching are what enable preservice and in-service teachers to distinguish between the formal and material elements of teaching. I have posited that being able to distinguish between the contextual constraints of a particular classroom and the core work that is a mainstay in all classrooms sets teachers up to be able to cope in a diverse array of classroom contexts. I now go on to present the research methodology for this article.

\section{Research methodology}

The research tool, data, and findings of this study are drawn from my recently completed doctoral study. Here, I report on one of the findings of this doctoral study-differently qualified pre-service teachers justify their grounds for their episodes of pedagogic reasoning 
(Horn, 2010) in different contexts. While my doctoral study used data from a much larger sample and set of findings, in this methodology section I present an argument for the research methodology of this article, which is one strand of the tapestry of my doctoral study.

This was a qualitative case study, which approach holds the benefit of avoiding the fragmentation of complex dynamic relationships, and contextual factors at play in specific cases, which require deep investigation (Sturman, 1999). While often critiqued because they cut down the generalisability of research findings, qualitative research case studies facilitate the study of situations that quantitative or numerical research simply cannot address adequately (Cohen, et al., 2007). ${ }^{1}$

Participants had completed their initial teacher education programmes but had not yet begun teaching in their first qualified teaching positions. They were drawn from two routes into teaching: four participants had recently completed a full-time four-year Bachelor of Education degree and three participants had studied either a Bachelor of Education or oneyear Post-graduate Certificate in Education part-time in conjunction with a learnership model in which pre-service teachers spend their days in a classroom as a teaching assistant. It is important to note that I do not compare the two routes but look, rather, at the implications of different forms of pedagogic reasoning. Therefore, the analysis of the data will not indicate which data was gleaned from which participant group. Each of the participants was invited to watch the same video of a Grade 8 geography lesson on climate that was filmed in an innercity Johannesburg school. The lesson was taught by a pre-service teacher, to whom I gave the pseudonym Ms Mdluli.

The participants were asked to respond to Ms Mdluli's teaching in a focus group in which they discussed their thoughts about her teaching with colleagues who had travelled the same route as they had. Here, I present and compare a piece of data from each focus group conversation. In the focus group interviews participants discussed what they felt Ms Mdluli should start doing in her teaching, what she should stop doing, and what she should continue to do. I analysed each of the participants' episodes of pedagogic reasoning from the focus groups using the semantic gravity analytic tool to develop a picture of the ways in which they rationalised their thoughts about the lesson in the video. I chose the pieces of data that are presented in this article because they were a good representation of the overall findings of the semantic gravity analyses of each participant group. In the next section, I present a research tool that can be used to unpack the semantic gravity of episodes of pedagogic reasoning, that reveal the context-embeddedness of the justifications of such pedagogic reasoning.

\section{Semantic waves as a tool for analysing pedagogic reasoning}

Here, I present the tool I used to analyse how pre-service teachers' episodes of pedagogic reasoning drew on different contexts or abstracted concepts to justify their thinking. First, I introduce the conceptual framework from which the tool is drawn (Maton's (2014)

1 Ethical clearance was obtained from the Wits School of Education's Ethics Committee before participants were contacted and research processes commenced. Protocol number 2014ECE53M. 
Legitimation Code Theory, henceforth LCT), and offer the argument that LCT's concept of semantic gravity enables one to distinguish analytically between the ways in which episodes of pedagogic reasoning are contextually-bounded or not. Thereafter, I present a "translation device" (Maton \& Chen, 2016, p. 27) that is a tool used to analyse the contextualboundedness of an episode of pedagogic reasoning.

LCT is "a sociological framework for researching and informing practice" (Maton, 2014, p. 182 ), and provides a set of conceptual tools with which to explore the grounds on which social practices are legitimised. LCT is a framework of concepts that act as an "explanatory framework," (Maton, 2014, p. 182) that does not profess to lend itself to any specific area of research. Since teaching is a socially constructed practice (Morrow, 1996) in which teachers (as knowers) work with knowledge, there have been many studies using LCT to analyse a range of teaching practices from the teaching of ballet, to music, to engineering. However, there have been no studies so far that seek to investigate the different ways in which the judgements in the context of newly qualified pre-service teachers are legitimised.

For the purposes of this article, I use one of LCT's concepts, namely semantic gravity, from its Semantics dimension. This property, ranging from stronger (+) to weaker (-), reveals the organising structure of knowledge. I use the concept of semantic gravity to analyse the shifts in the context dependence of beginner teachers' pedagogic reasoning. It is important to note that the Semantics dimension describes meaning through two concepts-semantic gravity and semantic density. In my doctoral study from which this paper is drawn, I used both these concepts to analyse pre-service teachers' episodes of pedagogic reasoning, but for the purposes of this article, I used only semantic gravity.

According to Maton (2014), all knowledge has semantic gravity (SG); this refers to "the degree to which meaning relates to its context" (p. 2). The easier it is to transfer a concept from the context in which it is given meaning, the weaker its semantic gravity (and the concept is relatively more abstract). The more difficult it is to transfer a concept or practice out of the context in which it has meaning, the stronger its semantic gravity (and the concept is relatively less abstract). Semantic gravity enables me to explore the extent to which the justification of the pedagogic reasoning of newly qualified pre-service teachers is grounded in relation to a specific contextual manifestation of teaching. The concept that is used to designate the extent to which the justification is tied to a context is the "situational appreciation" (Morrow, 1996, p. 80) that the participants show. It also allows me to conceptualise the extent to which the participants abstract their criteria for good teaching from the context of the lesson. Using the concept of semantic gravity, the various ways in which pre-service teachers express their judgements can be described in terms of various strengths of semantic gravity. LCT studies use "translation devices" (Maton, 2016a) to "transcend the divide between theory and data" (Maton \& Chen, 2016, p. 32) to relate concepts that are being explored in a study "to something beyond a theoretical framework" (Maton, 2016b, p. 243). A translation device delineates relative strengths of one concept, in this case, semantic gravity, with indicators for each strength to make the manifestation of the LCT concept in the data as clear as possible. For each strength of semantic gravity, I provide 
an example from the original dataset of my doctoral study to further clarify the indicators of the strength of semantic gravity. In this study, four levels of semantic gravity can be defined, as seen in Table 1.

\section{Table 1}

Translation device for semantic gravity of episodes of pegagogical reasoning

\begin{tabular}{|c|c|c|c|}
\hline Strength & \multicolumn{2}{|r|}{ Description } & \multirow{2}{*}{$\begin{array}{l}\text { Example from data } \\
\text { “. . . instead of just using } \\
\text { learners' everyday examples in } \\
\text { terms of explaining temperature } \\
\text { maybe start with their everyday } \\
\text { knowledge . . to maybe lead to } \\
\text { their understanding of } \\
\text { temperature and climate” }\end{array}$} \\
\hline $\begin{array}{l}\text { Weaker } \\
\text { SG } \\
\text { (SG -) }\end{array}$ & 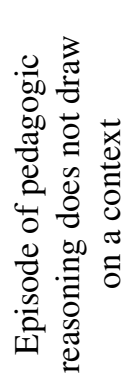 & $\begin{array}{l}\text { Episode of pedagogic reasoning draws on } \\
\text { principle or rule of practice: The episode of } \\
\text { pedagogic reasoning is completely abstracted } \\
\text { from a context since it grounds its judgement in } \\
\text { a principle or rule of practice }\end{array}$ & \\
\hline $\begin{array}{l}\text { Strong } \\
\text { SG } \\
(\mathbf{S G}+)\end{array}$ & \multirow{3}{*}{ 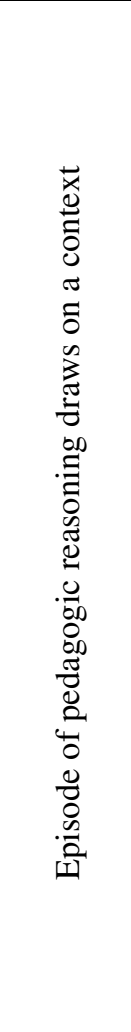 } & $\begin{array}{l}\text { Episode of pedagogic reasoning draws on } \\
\text { situational appreciation of a hypothetical } \\
\text { context (if . . . then reasoning): Pre-service } \\
\text { teacher shows a kind of situational appreciation } \\
\text { by imagining a situation in which a given } \\
\text { problem might be apparent. Ideas deduced from } \\
\text { the hypothetical context are drawn on and } \\
\text { applied to a given context }\end{array}$ & $\begin{array}{l}\text { “... when you call out to a } \\
\text { learner, all the learners stop, and } \\
\text { when you come back now } \\
\text { learners don't know what you } \\
\text { were talking about, you have to } \\
\text { restart" }\end{array}$ \\
\hline $\begin{array}{l}\text { Stronger } \\
\text { SG } \\
(\mathbf{S G}++)\end{array}$ & & $\begin{array}{l}\text { Episode of pedagogic reasoning draws on a real- } \\
\text { life context (own experience): Pre-service } \\
\text { teacher shows situational appreciation of own } \\
\text { experiences as a pre-service teacher during } \\
\text { practical teaching experiences, and applies } \\
\text { lessons learned from that situational } \\
\text { appreciation to another context }\end{array}$ & $\begin{array}{l}\text { "I've had rowdy classes where it } \\
\text { is just noise for an entire } 40 \\
\text { minutes." }\end{array}$ \\
\hline $\begin{array}{l}\text { Very } \\
\text { strong } \\
\text { SG } \\
\text { (SG+++) }\end{array}$ & & $\begin{array}{l}\text { Episode of pedagogic reasoning draws on } \\
\text { situational appreciation of a given context } \\
\text { (putting myself in someone else's experience): } \\
\text { Pre-service teacher shows situational } \\
\text { appreciation of the given context, and applies } \\
\text { ideas learned from that situational appreciation } \\
\text { to the given context }\end{array}$ & $\begin{array}{l}\text { "... she mentioned the headings } \\
\text { on each of the worksheets or } \\
\text { hand-outs and then said, 'so } \\
\text { that's what we are going to do } \\
\text { today'." }\end{array}$ \\
\hline
\end{tabular}

So far, in this article I have argued for the centrality of pedagogic reasoning in professional teaching practice has and have highlighted the problem that pedagogic reasoning is not wellunderstood and therefore difficult to teach. I now move on to an analysis of some data from my original doctoral study as a basis for the argument of this article: pedagogic reasoning can be represented by semantic waves that shift in their context dependence. They enable beginning teachers to distinguish between the formal and material elements of teaching and, therefore, they may be in a better position to cope in changing classroom contexts. 
Langsford: Coping in complex, changing classroom contexts

61

An analysis of examples of episodes of pedagogic reasoning and their implications

To show first how the tools of analysis were enacted, and second how I deduced the findings that are presented in this paper, I present the analysis of two episodes of pedagogic reasoning from the focus group interviews. I also discuss the findings of the analysis in relation to the literature and overall argument of this article, which is that being able to distinguish between the contextual constraints of a particular classroom and the core work that is a mainstay in all classrooms sets teachers up to be able to cope in a diverse array of classroom contexts.

I first present the semantic gravity profile of a typical exemplar episode of pedagogic reasoning from a focus group discussion with Group A. This was a discussion between Leticia, Ashley, and Tshepo, although Tshepo did not speak in this part of the focus group interview. The participants were discussing what Ms Mdluli should start doing in her teaching to improve it. The profile shows little waving between the justification of pedagogic reasoning drawing on the context of the lesson which was observed by participants and other contexts or ideas.

Figure 1

Semantic profile of Group A's conversation

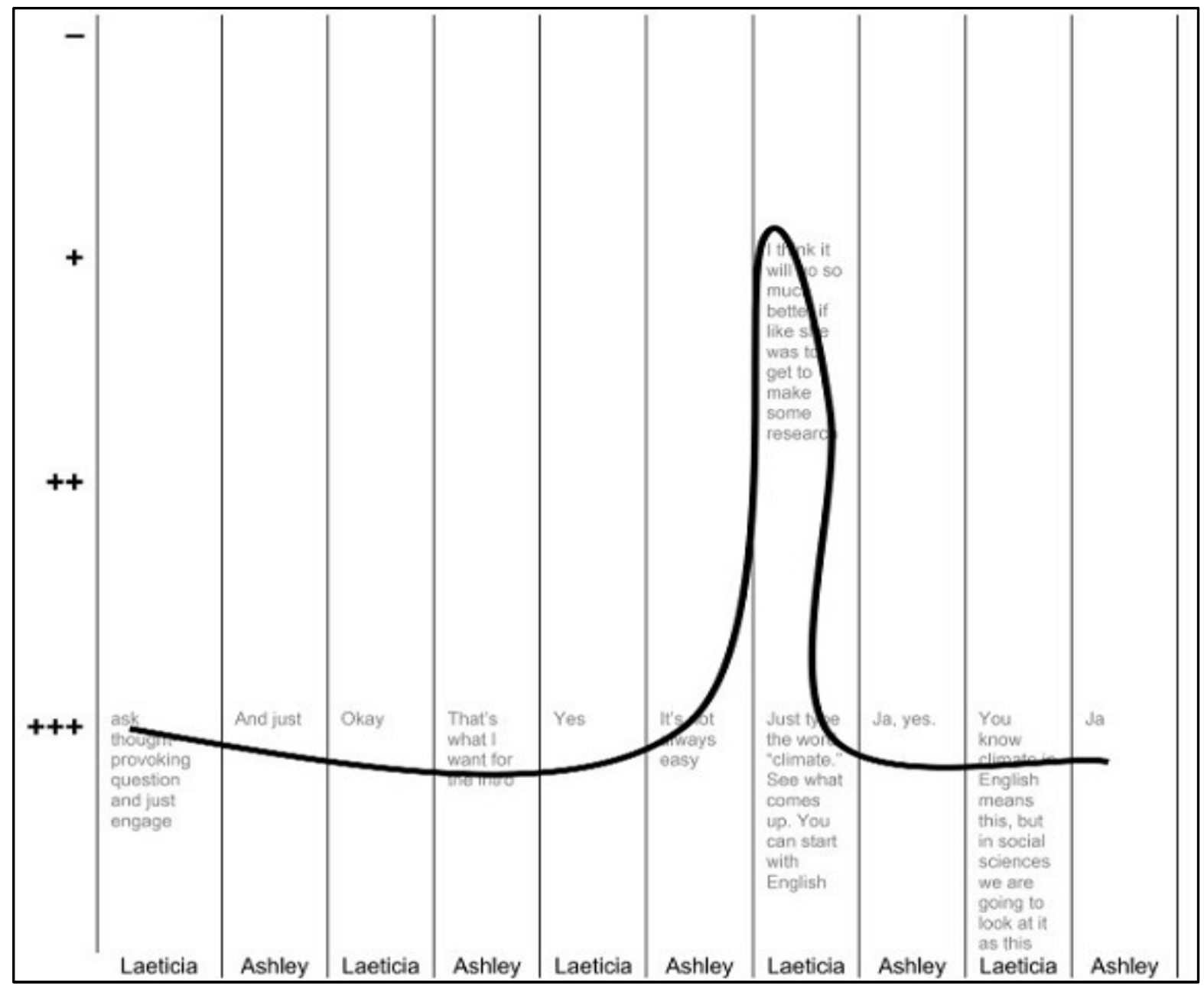


Group A's participants' conversation is in relation to Ms Mdluli's use of relevant examples to make the knowledge more accessible to learners, and so, naturally, the context of the observed lesson is the topic on which their conversation begins; the participants hardly draw on any other contexts to justify their pedagogic reasoning. This means that their pedagogic reasoning tends to be very strongly contextually bounded and does not draw upon lesscontextual ideas or principles to make sense of a teaching and learning event. The detailed analysis of the conversation below reveals how the participants tended to ground their justifications in the context of the observed lesson throughout their conversation.

Table 2

Semantic gravity analysis of Group A's conversation

\begin{tabular}{|c|c|c|}
\hline & Group A's focus group discussion & Analysis \\
\hline Laeticia: & $\begin{array}{l}\text { So ... . ask thought-provoking questions, and just } \\
\text { engage. . . }\end{array}$ & $\begin{array}{l}\text { Feedback directly in relation to the } \\
\text { lesson that was observed. SG+++ }\end{array}$ \\
\hline Ashley: & And just ... & \\
\hline Laeticia: & Okay. & Agreement that this is appropriate \\
\hline Ashley: & Ja. That's what I want for the introduction. & feedback in the context of the lesson. \\
\hline Laeticia: & For an introduction. Yes. & SG+++ \\
\hline Ashley: & It's not always easy. . . introducing. & \\
\hline \multirow[t]{2}{*}{ Laeticia: } & $\begin{array}{l}\text { Ja, I know it is not always easy, but I think it will } \\
\text { go so much better if like she was to get, to make } \\
\text { more research. Because it, it's not easy getting } \\
\text { visual aids, but just, you read books - you're a } \\
\text { teacher, right? You read books. These days we } \\
\text { have access to the internet. Find something in the } \\
\text { internet that is like, that has better explanation than } \\
\text { what you see in a textbook. I think that when you } \\
\text { present a lesson, you know, you see a textbook } \\
\text { first - you read a textbook. }\end{array}$ & $\begin{array}{l}\text { Justification for episode of pedagogic } \\
\text { reasoning is grounded in a hypothetical } \\
\text { context - "IF she was to. . ."; "WHEN } \\
\text { you present. . " Laeticia gives advice } \\
\text { that is specifically applicable to a } \\
\text { hypothetical scenario. SG+ }\end{array}$ \\
\hline & $\begin{array}{l}\text { So, go on the internet. Just type the word, } \\
\text { "climate." See what comes up. You know, you } \\
\text { can... you can even not just define it in a social } \\
\text { science kind of point of view. You can start with } \\
\text { English. }\end{array}$ & $\begin{array}{l}\text { Laeticia's justification then moves back } \\
\text { to the specific context of the lesson on } \\
\text { climate that she observed and how her } \\
\text { earlier advice is applicable in this } \\
\text { lesson. SG+++ }\end{array}$ \\
\hline Ashley: & Ja, yes. & $\begin{array}{l}\text { Agreement that this is suitable feedback } \\
\text { in the context of this lesson. SG+++ }\end{array}$ \\
\hline Laeticia: & $\begin{array}{l}\text { Just say, "You know climate in English means } \\
\text { this, but in social sciences we are going to look at } \\
\text { it as this, and this, and this, and this, and this... }\end{array}$ & $\begin{array}{l}\text { Reinforcement of the feedback in } \\
\text { relation to the context of this lesson. } \\
\text { SG+++ }\end{array}$ \\
\hline Ashley: & Ja. & $\begin{array}{l}\text { Agreement that this is suitable feedback } \\
\text { in the context of this lesson. SG+++ }\end{array}$ \\
\hline
\end{tabular}

A typical episode of pedagogic reasoning for Group A in this study could then be described as having very strong semantic gravity which occasionally weakens to having strong semantic gravity. Typically, Group A's participants' pedagogic reasoning does not abstract to an abstracted principle or rule of teaching. These participants show high levels of situational appreciation (Morrow, 1996) since their pedagogic reasoning about a particular learning 
event is justified by the contextual realities of the learning situation in which the lesson is to take place. The reasons for their decisions about the lesson that they observed often come from their ". . . perception of what is salient in [this] particular [situation]" (Morrow, 1996, p. 80). While the likes of Morrow (1996) and Shulman (1987) agree that developing "professional judgements that take informed account of the details of particular situation" (Morrow, 1996, p. 80) is important in the preparation of teachers, the downplaying of abstracted theoretical ideas when they are thinking about teaching may inhibit Group A's participants' ability to distinguish between the formal and material elements of teaching.

It may be that participants in Group A do have access to context-independent principles of teaching, but do not explicitly draw on them (or they are latent). However, if the criteria for pedagogic decision making comes from situational appreciation of a particular context alone, the criteria for good teaching are not necessarily transferable to other contexts. When the criteria for good teaching are not transferrable, the possibilities of context switching (that is, organising systematic learning in another teaching and learning situation) may be cut down since the criteria for good teaching are no longer present or look different. The constraints under which decisions about this lesson were made may be different in another lesson, another classroom, another school, or another country. When there is no organising framework (given by context-independent principles of teaching, or what Morrow (2005, p. 98) calls the "formal elements" of teaching) brought to bear on a pre-service teacher's thinking about teaching, teaching becomes organised by the practice itself.

Figure 2

Semantic profile of Group B's conversation

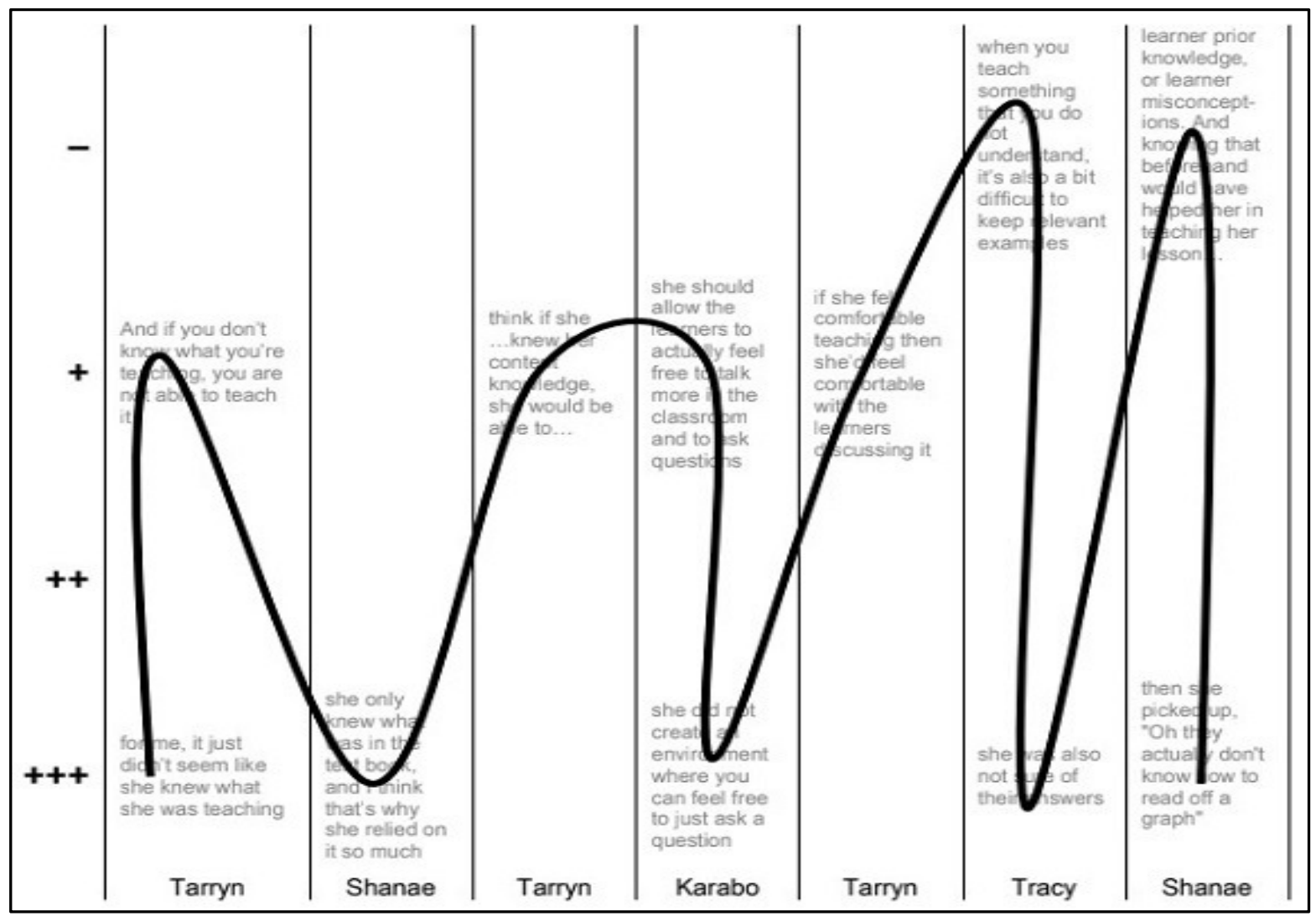


I now present the analysis of a typical Group B episode of pedagogic reasoning. First, I present the semantic gravity profile of the conversation to guide the analysis of the episode of pedagogic reasoning. This was a discussion between Karabo, Shanae, Tarryn, and Tracy. The participants were discussing what Ms Mdluli should start doing in her teaching to improve it, but the conversation included things that she should stop doing consequently as well.

While Group B's participants' conversation is in relation to Ms Mdluli's content knowledge, and so the context of the video is where their conversation begins, the participants engage in semantic waving, between the context of the lesson and the hypothetical, before abstracting to networked principles at the end of the excerpt. The detailed analysis of the conversation below reveals how the participants created that semantic wave throughout their conversation.

Table 3

Semantic gravity analysis of Group B's conversation

\begin{tabular}{|c|c|c|}
\hline & Group B's focus group discussion & Analysis \\
\hline Tarryn: & $\begin{array}{l}\text { Um, well for me it just didn't seem like she knew what } \\
\text { she was teaching. } \\
\text { And if you don't know what you're teaching, you're not } \\
\text { able to teach it, and then the learners can pick it up, and } \\
\text { they're not able to learn. And you can't answer } \\
\text { questions, and she didn't know where she was, or like } \\
\text { definitions, I don't. . So if she just took the time to } \\
\text { learn about what she was supposedly teaching, then she } \\
\text { would have been able to teach it a lot more confidently } \\
\text { as well, and be able to handle discipline matters better, } \\
\text { and you know, let the children answer the question. She } \\
\text { wouldn't have to figure it out for herself. Then she'd be } \\
\text { able to know when the fact that the children aren't } \\
\text { reading graphs, and that they don't. . like they don't } \\
\text { know that stuff. Just by knowing what she wants to } \\
\text { teach them. }\end{array}$ & $\begin{array}{l}\text { Feedback is in relation to the context } \\
\text { of the observed lesson. SG+++ } \\
\text { The justification for Tarryn's feedback } \\
\text { is grounded in a hypothetical context - } \\
\text { "IF you don't know. . "; "IF she just } \\
\text { took the time. . THEN she would } \\
\text { have been able to. . " SG+ }\end{array}$ \\
\hline Shanae: & $\begin{array}{l}\text { I agree with Tarryn. Um, it felt like she only knew what } \\
\text { was in the textbook, and I think that's why she relied on } \\
\text { it so much. So, there was no deeper knowledge - um - } \\
\text { into that. And then, um, even right at the beginning of } \\
\text { the lesson, when she asked the learners "what is } \\
\text { climate?" um one of the learners actually responded } \\
\text { with the exact same definition she gave them later on. } \\
\text { Um, but she had said to the learner that they were } \\
\text { incorrect. So, it just - I think she was searching for one - } \\
\text { she was searching for one answer, and maybe it was } \\
\text { slightly out in terms of the way they phrased it, and } \\
\text { then she just discarded it. Um, so ja it was very evident } \\
\text { that her, she needs to start reading deeper - getting to } \\
\text { know content before she actually teaches it. }\end{array}$ & $\begin{array}{l}\text { Shanae reverts to the context of the } \\
\text { lesson by speaking about what she } \\
\text { observed as a justification for her } \\
\text { reasoning that Ms Mdluli needs to } \\
\text { deepen her content knowledge. } \\
\text { SG+++ }\end{array}$ \\
\hline
\end{tabular}


Tarryn: I agree. I think if she, like Shanae said, knew her content knowledge, she would be able to pick up that the children have made their own understanding, and that they actually do understand and ... stuff ... ja.

Karabo: I agree with what you guys are saying - uh Tarryn and Shanae, that uh she should have indeed like prepared the content thoroughly, and I also feel like she should allow the learners to actually feel free to talk more in the classroom and to ask questions.

Because I felt like that was - she did not create an environment where you can feel free to just ask a question.

Tarryn: I think that would come with; you know if she felt comfortable teaching then she'd feel comfortable with the learners discussing it.

Tracy: I also agree. Because when you teach something that you do not understand, it's also a bit difficult to keep uh relevant examples.

also feel that even though she was asking those questions, at some point she was also not sure of their answers, because learners get different answers, and she would say "Oh, twenty-five degrees, maybe twentysix."

Shanae: I agree with what you're saying, Tracy. Um, and I think it also comes down to her lesson preparation. Um, there was absolutely nothing in her lesson plan about learner um prior knowledge, or learner misconceptions. And knowing that beforehand would have helped her in teaching her lesson. Cause then she'd know which examples to use, um, that would be relevant to the learners. She'd pick up on where they might have difficulty in the lesson.

Um, so I think only as the lesson went on, then she picked up, "Oh they actually don't know how to read off a graph," and then the explanation after that I don't think was good enough.
Tarryn justifies this same point that Ms Mdluli needs to deepen her content knowledge by drawing on another hypothetical context - "IF she knew .. . she would be able to. .."SG+

Karabo picks this point up, justifying her reasoning by giving another hypothetical of what Ms Mdluli should do - "she SHOULD HAVE. .." SG+ Further justification reports observations of the context of the lesson. SG+++

The justification is hypothetical - IF she felt comfortable... THEN she'd feel. .. "SG+

Tracy justifies her reasoning using an abstracted principle of teaching which is that examples need to be accessible to learners. SG-

She then moves her justification to what she observed in the context of the video. SG+++

Shanae justifies her agreement with Tracy by using an abstracted principle of teaching, which is that lesson preparation needs to consider learners' prior knowledge and experiences. SG-

The justification moves back to the context of the lesson which was observed. SG+++

Group B's conversation moves between and among the context of the observed lesson, hypothetical teaching and learning contexts, and abstracted principles and ideas. What sets Group B's conversation and justifications for their pedagogic reasoning apart from Group A's is that Group B make these moves between the context of the observed lesson and abstract principles of teaching. When pre-service teachers have access to context-independent, systematised educational theory and theoretical principles of teaching, they are in a better position to be able to distinguish between the formal and material elements of teaching (Morrow, 1996).

Abstracted principles and concepts of teaching are "contextually responsive but not contextually bound" (Rusznyak, 2015, p. 21) and enable pre-service teachers to distinguish between the formal and material elements of teaching which "are necessarily rooted in 
specific contexts" (Morrow, 2005, p. 98). In the case of Group B's conversation presented here, the participants show not only an awareness of what is important in this lesson, but the criteria for their justification of their pedagogic reasoning is drawn from the lesson itself, hypothetical contexts, and context-independent principles of teaching. In Rusznyak's (2015, p. 21) words, Group B's participants take abstracted principles (which are "not contextually bound") and use them in "contextually responsive" ways. Based on this logic, Group B's participants may be in a privileged position when it comes to being able to engage in intentional decision-making in their own classrooms. Because Group B's participants use context-independent principles and theories of teaching, they are in a better position to be able to navigate the changing demands of classroom life because they have a conceptual toolkit with which to make sense of a variety of contexts that they face.

\section{Conclusion}

In this article, I have presented a set of analytical tools to unpack the abstraction and complexity of two episodes of pedagogic reasoning. The tool I used is the semantic gravity concept of the Semantics dimension of LCT. The tool was employed to show the abstraction and context-boundedness of episodes of pedagogic reasoning of two groups of pre-service teachers. I argue that pre-service teachers who are able to access and engage with complex, context-independent theoretical ideas in relation to a teaching and learning context are more likely to be able to distinguish between the formal and material elements of teaching.

Analysis of the data shows that Group A's participants' justifications for their episode of pedagogic reasoning indicated that they drew on ideas from the context of the observed lesson itself, and occasionally drew criteria from hypothetical teaching contexts. Group B's participants justified their pedagogic reasoning by drawing on contextual cues from the lesson that they observed, hypothetical contexts, and ideas that are abstracted from the context about which they were reasoning. Furthermore, Group B's participants moved between context-independent, hypothetical contexts, and the context of the observed lesson to justify their pedagogic reasoning. I have argued that the ability to make this distinction is likely to enable teachers to cope in diverse teaching contexts.

I propose that because they have access to theoretical ideas about teaching, Group B's participants may be at an advantage when distinguishing between the formal and material elements of teaching because they have access to an organising framework when they are organising systematic learning (Morrow, 2005). By being able to distinguish the formal and material elements of teaching, participants in Group B may be in a better position to have access to the principles of good teaching that are a mainstay in any classroom. A suggested further area of study is enquiry into the ways in which complex context-independent principles and theories of teaching enable practicing teachers to engage in pedagogic reasoning to promote epistemological access to powerful learning for all learners in their classrooms. 


\section{References}

Bransford, J., Darling-Hammond, L., \& LePage, P. (2005). Introduction. In L. DarlingHammond, \& J. Bransford (Eds.), Preparing teachers for a changing world: What teachers should learn and be able to do (pp. 1-39). Jossey-Bass.

Cohen, L., Manion, L., \& Morrison, K. (2007). Research methods in education. Routledge.

Horn, I. S. (2010). Teaching replays, teaching rehearsals, and re-visions of practice: Learning from colleagues in a mathematics teacher community. Teachers College Record, 112(1), 225-259.

Hugo, W. (2013). What is selection and is it open or closed? In W. Hugo (Ed.), Cracking the code to educational analysis (pp. 57-72). Pearson.

Langsford, D. (2020). 'Those who can think, teach': The pedagogical reasoning of preservice teachers from different initial teacher education pathways (Unpublished doctoral dissertation). University of the Witwatersrand, Johannesburg.

Maton, K. (2014). Knowledge and Knowers: Towards a realist sociology of education. Routledge.

Maton, K. (2016a). Building knowledge about knowledge-building. In K. Maton, S. Hood, \& S. Shay (Eds.), Knowledge-building: Educational studies in Legitimation Code Theory (pp. 1-23). Routledge.

Maton, K. (2016b). Resources and architectural glossary. In K. Maton, S. Hood, \& S. Shay (Eds.), Knowledge building: Educational studies in Legitimation Code Theory (pp. 234-243). Routledge.

Maton, K., \& Chen, R.T-H. (2016). LCT in qualitative research: Creating a translation device for studying constructivist pedagogy. In K. Maton, S. Hood \& S. Shay (Eds.), Knowledge-building: Education studies in Legitimation Code Theory (pp. 27-48). Routledge.

Morrow, W. (1992). A picture holds us captive. In W. Morrow, Learning to teach in South Africa (pp. 37-50). Human Sciences Research Council Press.

Morrow, W. (1996). What is teacher education? In W. Morrow, Learning to teach in South Africa (pp. 69-90). Human Sciences Research Council Press.

Morrow, W. (2005). What is teachers' work? In W. Morrow, Learning to teach in South Africa (pp. 3-20). Human Sciences Research Council Press. 
Reeves, C., \& Robinson, M. (2014). Assumptions underpinning the conceptualisation of professional learning in teacher education. South African Journal of Higher Education, 28(1), 236-253.

Rusznyak, L. (2015). Knowledge selection in initial teacher education programmes and its implications for curricular coherence. Journal of Education,60, 7-30.

Rusznyak, L., \& Walton, E. (2011). Lesson planning guidelines for student teachers: A scaffold for the development of pedagogical content knowledge. Education as Change, 15(2) 271-285.

Shalem, Y. (2014). What binds professional judgement? The case of teaching. In M. Young, \& J. Muller (Eds.), Knowledge, expertise and the professions (pp. 93-105). Routledge.

Shulman, L. S. (1987). Knowledge and teaching: Foundations of the new reform. Educational Researcher, 15(2), 14-44.

Shulman, L. S. (1998). Theory, practice, and the education of professionals. The Elementary School Journal, 98(5), 511-526.

Shulman, L. S. (1999). Taking learning seriously. Change, 31(4), 10-17.

Sturman, A. (1999). Case study methods. In J. P. Keeves, \& G. Lakomski (Eds.), Issues in educational research (pp. 103-112). Elsevier Science.

Winch, C. (2012). For philosophy of education in teacher education. Oxford Review of Education, 38(3), 1-18. 